\title{
ANAESTHETIC MANAGEMENT OF PHEOCHROMOCYTOMA: A CASE REPORT
}

\author{
Gary L. Fanning, M.D., Michael H. M. Dykes, M.B., B.ChIR., aND \\ Allyn G. MAX, M.D.*
}

The anaesthetic management of patients with pheochromocytoma has become increasingly sophisticated in recent years, thanks to the introduction of a variety of drugs which allow selective inhibition of responses to abnormally high levels of circulating catecholamines. Preoperative and intraoperative alpha and beta adrenergic block, improved intraoperative monitoring, fluid and blood infusion therapy, and employment of anaesthetic agents which do not sensitize the myocardium to circulating catecholamines have all contributed to reducing the dangers of uncontrollable hypertension and serious cardiac arrhythmias during removal of these tumours.

The following case report describes our recent experience with a patient with pheochromocytoma and illustrates the principles of management advocated in the current medical literature.

\section{Case Report}

A 43-year-old woman was referred to the University of Rochester Medical Center with a presumptive diagnosis of pheochromocytoma. Though intermittently hypertensive for ten years, she had become persistently hypertensive during the year prior to admission. Additional symptoms included nervousness, increased perspiration, episodes of palpitations, decreased vision in the right eye, slight weight loss, and one episode of "vascular headache." Further history revealed that the patient's mother had suffered from hypertension and a "stroke," and two of her sisters were said to be suffering from hypertension. Physical examination revealed a well-developed, alert, co-operative white female, whose blood pressure was $200 / 125 \mathrm{~mm} \mathrm{Hg}$ and pulse rate 72 beats per minute. The maximum recorded blood pressure preoperatively was $250 / 160 \mathrm{~mm} \mathrm{Hg}$. Other physical findings included a fine tremor of the outstretched hands, bilateral retinopathy with papilloedema, and a right upper quadrant abdominal mass. No Cushingoid features were present.

Laboratory findings. The admission haemogram (haematocrit 39 per cent), blood urea nitrogen, serum electrolytes, serum glutamic oxalacetic transaminase, and alkaline phosphatase levels were within normal limits. The fasting blood sugar level was $169 \mathrm{mg}$ per $100 \mathrm{ml}$, and the glucose tolerance test levels were elevated. The electrocardiogram was interpreted as normal sinus rhythm, left

'Dr. Fanning is Chief Resident and Research Fellow in the Department of Anesthesiology, University of Rochester School of Medicine and Dentistry, Rochester, New York. Dr. Dykes is Assistant Professor of Anesthesiology; present address: Beth Israel Hospital, Boston, Massachusetts. Dr. May is Assistant Professor of Surgery, University of Rochester School of Medicine and Dentistry, and Associate Surgeon, Strong Memorial Hospital, Rochester, New York. 
ventricular hypertrophy, and s-T and $\mathrm{T}$ wave changes consistent with left ventricular hypertrophy and/or anterolateral ischaemia. Total urinary catecholamine excretion was $1260 \mu \mathrm{g}$ per day (normal value $30-100 \mu \mathrm{g}$ per day). The urinary norepinephrine excretion was $1383.5 \mathrm{Ng} / \mathrm{min}$ or $335.4 \mathrm{Ng} / \mathrm{ml}$ (normal value: approx. $30 \pm 10 \mathrm{Ng} / \mathrm{min}$ ), and the urinary vanillylmandelic acid (vMA) excretion was $21 \mathrm{mg}$ per day (normal value: less than $10 \mathrm{mg}$ per day). The baseline urinary 17-hydroxycorticoid excretion was $3.6 \mathrm{mg}$ per day (normal value: 4-10 mg per day), and the plasma cortisol level was $9 \mu \mathrm{g}$ per $100 \mathrm{ml}$ (normal value: $5-20 \mu \mathrm{g}$ per $100 \mathrm{ml}$ ). An intravenous pyelogram revealed a mass above the right kidney. Aortography demonstrated a single, large $(12 \mathrm{~cm} \times 9 \mathrm{~cm})$, well-encapsulated tumour mass with irregular vessels, some A-v shunting, and central cystic necrosis. The mass was displacing the right kidney downwards and was supplied by the right adrenal artery. The combined historical, physical, and laboratory findings were consistent with the diagnosis of pheochromocytoma of the right adrenal gland.

Preparation with phenoxybenzamine, $30 \mathrm{mg}$ per day in divided doses, was started on the second hospital day. Propranolol, $60 \mathrm{mg}$ per day in divided doses, was added to the therapeutic regimen on the third hospital day. Both drugs were continued until midnight of the day prior to surgery. This therapy resulted in a rapid control of blood pressure to approximately $160 / 110 \mathrm{~mm} \mathrm{Hg}$, with cessation of both the episodes of palpitations and the increased perspiration, but without development of orthostatic hypotension.

The patient was premedicated with intramuscular pentobarbital (100 mg) and atropine $(0.5 \mathrm{mg})$ one hour prior to surgery on the twelfth hospital day. Two intravenous infusions of 5 per cent dextrose in lactated Ringer's solution were started, one of which was administered through a 21 inch catheter introduced into a central vein via the left basilic vein, allowing intermittent measurement of the central venous pressure with a saline manometer. An 18 gauge Teflon needle was inserted into the left radial artery for direct continuous measurement of the arterial pressure using a Sanborn physiologic pressure transducer. Both the electrocardiographic and arterial pressure tracings were displayed on an oscilloscope and recorded permanently throughout the procedure.

Anaesthesia was induced at 8:00 AM with thiopental sodium (150 mg) intravenously, followed by nitrous oxide and oxygen $(4: 2 \mathrm{~L} / \mathrm{min})$ and methoxyflurane. D-tubocurarine chloride $(3 \mathrm{mg})$ and succinylcholine chloride $(60 \mathrm{mg})$ were given at 8:05 $\mathrm{AM}$ and 8:12 $\mathrm{AM}$, respectively, to facilitate endotracheal intubation. Neither endotracheal intubation, passage of an oesophageal thermistor probe, nor insertion of a nasogastric tube were associated with any significant changes in the arterial pressure (Fig. 1). Anaesthesia was maintained with nitrous oxide and oxygen $(2: 2 \mathrm{~L} / \mathrm{min})$ and methoxyflurane ( $14-1$ per cent), using a semi-closed carbon dioxide absorption circle system and controlled ventilation (Air-Shields Ventimeter), Arterial blood gases were measured at 8:55 and 9:35 $\mathrm{AM}$ with the following results: (a) $\mathrm{pH} 7.34$ and 7.38, (b) $\mathrm{Po}_{2} 185 \mathrm{~mm} \mathrm{Hg}$ and $188 \mathrm{~mm} \mathrm{Hg}$, and $(c) \mathrm{PCO}_{2} 40 \mathrm{~mm} \mathrm{Hg}$ and $35 \mathrm{~mm} \mathrm{Hg}$, respectively. One additional injection of d-tubocurarine chloride $(9 \mathrm{mg})$ was required during closure of the abdominal wound. 


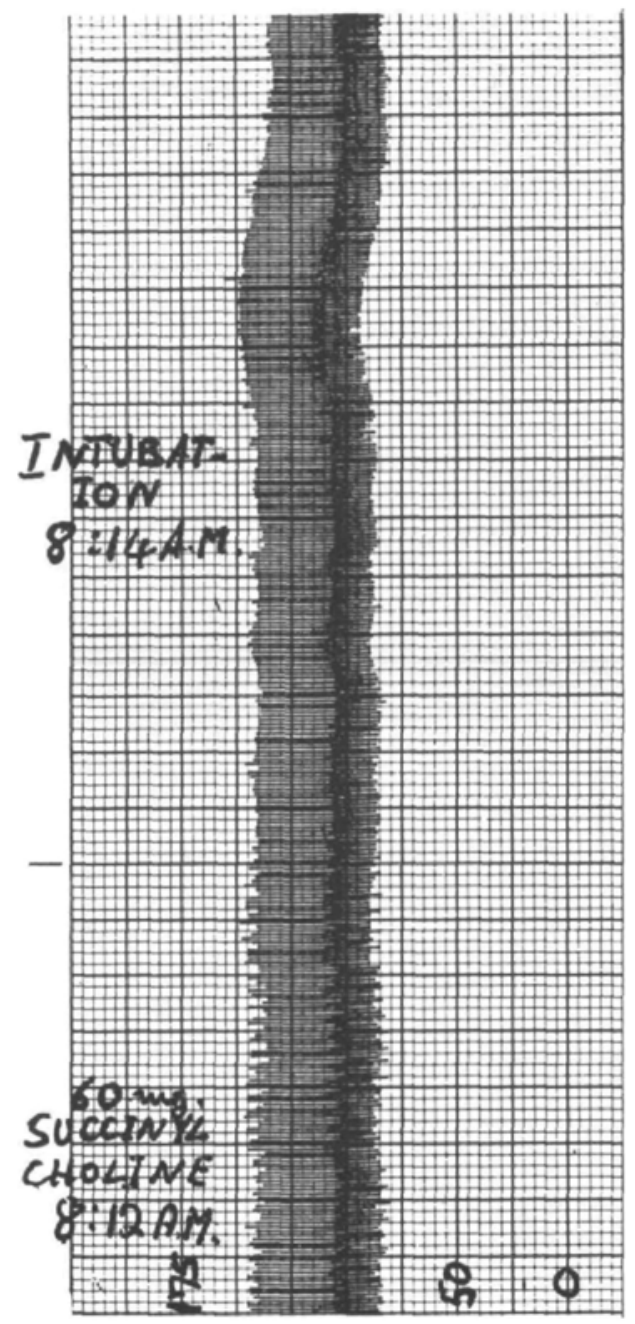

Figure 1. Arterial pressure tracing during endotracheal intubation (chart speed: 0.50 $\mathrm{mm} / \mathrm{sec}$ ).

Laparotomy was started at 8:25 AM. Neither palpation of the right adrenal tumour nor the initial dissection around it disturbed the arterial pressure (Fig. 2); however, extension of the abdominal incision into the thorax approximately one hour later resulted in a transient rise in pressure to $200 / 120 \mathrm{~mm} \mathrm{Hg}$. In this instance a gradual fall to $170 / 110 \mathrm{~mm} \mathrm{Hg}$ occurred without pharmacological intervention. It was necessary to divide the right triangular hepatic ligament in order to retract the right lobe of the liver anteriorly for adequate exposure of the tumour and its venous supply. During a period of difficult dissection around the tumour, the arterial pressure rose to $225 / 130 \mathrm{~mm} \mathrm{Hg}$, and two doses of intravenous phentolamine were required (Fig. 3). Following the ligation of the venous drainage and removal of the tumour, the arterial pressure gradually fell 


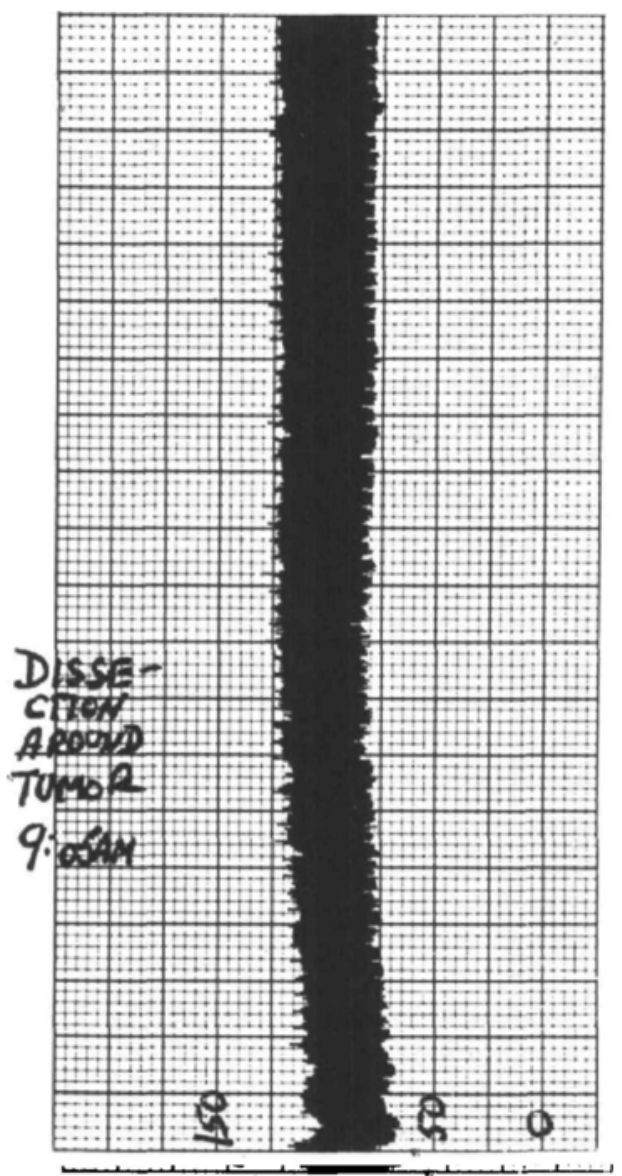

Ficure 2. Arterial pressure tracing during initial dissection around tumour (chart speed: $0.25 \mathrm{~mm} / \mathrm{sec}$ ).

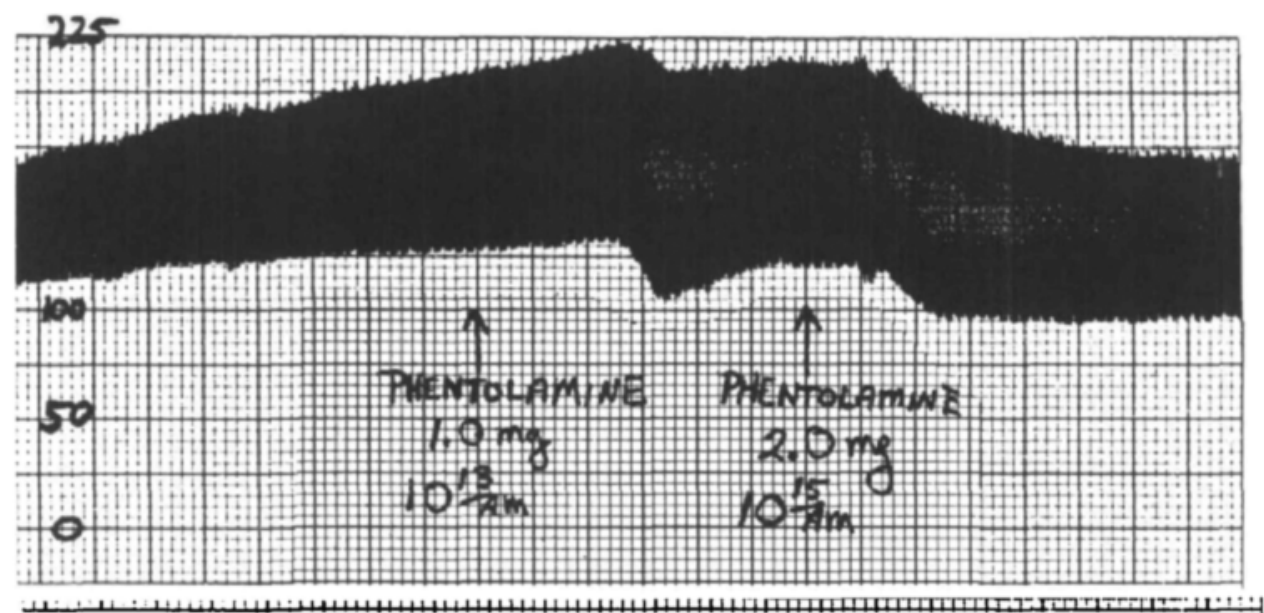

Figure 3. Arterial pressure tracing during manipulation of the tumour, demonstrating rapid response to intravenous phentolamine (chart speed: $0.25 \mathrm{~mm} / \mathrm{sec}$ ). 


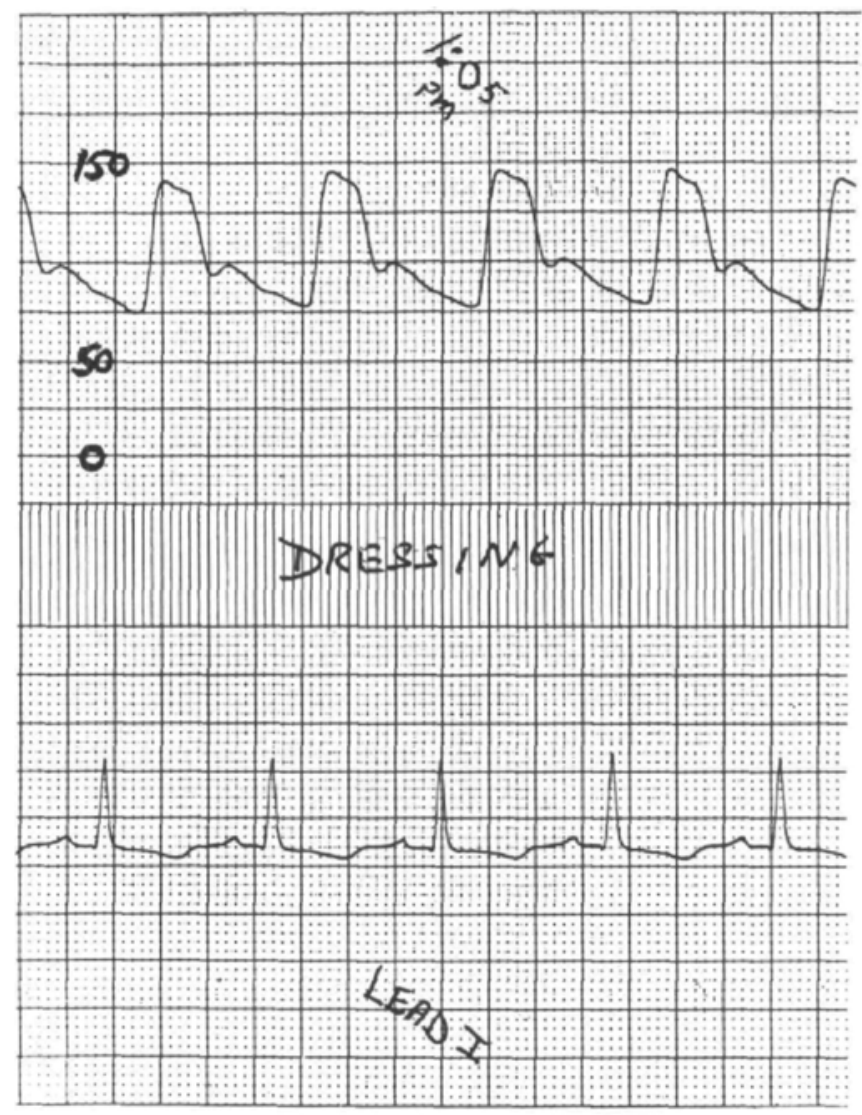

FIGURE 4. Arterial pressure tracing and lead 1 electrocardiographic tracing during application of the dressing (chart speed: $25 \mathrm{~mm} / \mathrm{sec}$ ).

to $80-100 / 50-60 \mathrm{~mm} \mathrm{Hg}$. Rapid infusion of both whole blood and lactated Ringer's solution during this period resulted in stabilization of the pressure at $110 / 65 \mathrm{~mm} \mathrm{Hg}$, without the use of vasopressors. Arterial pressure and electrocardiographic tracings taken during application of the dressing are shown in Figure 4. The latter depicts the normal sinus rhythm (70-100 beats per min) that was present throughout the procedure. No instance of ventricular irritability was either observed or recorded. The central venous pressure varied between 9 and $22 \mathrm{~cm} \mathrm{H}_{2} \mathrm{O}$, and the aesophageal temperature fell to $35^{\circ} \mathrm{C}$ during the procedure. An estimated blood loss of approximately $2000 \mathrm{ml}$ was replaced by $2500 \mathrm{ml}$ of warmed whole blood and $2700 \mathrm{ml}$ of 5 per cent dextrose in lactated Ringer's solution.

The tumour weighed $230 \mathrm{gm}$ and measured $10 \times 8 \times 6 \mathrm{~cm}$. It was cystic and contained $280 \mathrm{ml}$ of fluid. The norepinephrine content of the tumour was 37.7 $\mathrm{mg} / \mathrm{gm}$ and of the fluid $7393 \mathrm{Ng} / \mathrm{ml}$. No epinephrine was detected in either the tumour or the fluid.

The arterial pressure was $120-130 / 70-80$ during the first postoperative day but 
gradually rose to $140-160 / 90-100$ on the seventh postoperative day. The haematocrit was 41 per cent on the first postoperative day and remained stable. The patient was discharged in satisfactory condition on the ninth postoperative day, and her blood pressure was $150 / 95 \mathrm{~mm} \mathrm{Hg}$ on her most recent follow-up visit, three months later.

\section{Discussion}

It is apparent from numerous reports that preoperative treatment with adrenergic blocking agents plays an important role in the operative management of patients with pheochromocytoma. ${ }^{1-5}$ Alpha adrenergic block, in addition to reducing hypertension preoperatively and modifying responses to high levels of circulating catecholamines intraoperatively, also expands the intravascular volume in those patients in whom this has been decreased due to intense peripheral vasoconstriction..$^{1-5}$ Indeed, some patients will require transfusions with whole blood or packed red blood cells following alpha adrenergic block. ${ }^{5}$ Beta adrenergic block is indicated in those patients with arrhythmias (sinus tachycardia and/or frequent premature ventricular contractions) associated with high levels of circulating catecholamines. ${ }^{9-5}$ Harrison et al. ${ }^{4}$ have suggested the following criteria for preoperative use of adrenergic blocking agents in patients with pheochromocytoma:

\section{Beta adrenergic block}

1. pulse rate greater than 140 per minute

2. history of arrhythmias

3. frequent premature ventricular contractions

4. pure epinephrine secreting tumours

\section{Alpha adrenergic block}

1. blood pressure sustained greater than $200 / 130 \mathrm{~mm} \mathrm{Hg}$

2. frequent paroxysms of uncontrolled hypertension

3. use of beta adrenergic block

If beta adrenergic block is used alone in patients with pheochromocytoma, there may be a marked rise in the total peripheral resistance due to vasoconstriction secondary to unopposed alpha adrenergic activity. ${ }^{4}$ This rise in total peripheral resistance will significantly increase the work load of the left ventricle at a time when the inotropic effects of beta adrenergic stimulation are partially or wholly blocked. Simultaneous alpha adrenergic block reduces, or prevents, the rise in total peripheral resistance associated with beta adrenergic block. Thus, if beta adrenergic block is indicated, alpha adrenergic block must also be initiated.

A variety of anaesthetic techniques have been suggested for management of patients with pheochromocytoma. The use of agents which promote the release of endogenous catecholamines (diethyl ether, cyclopropane, and trichlorethylene $\mathrm{e}^{\mathrm{b}-8}$ ) or which sensitize the myocardium to high levels of circulating catecholamines (cyclopropane, trichloroethylene, and halothane ${ }^{a-8}$ ) has been associated with a high incidence of cardiac arrhythmias and severe hypertension during surgery for pheochromocytoma., ${ }^{2,5}$ Agents such as methoxyflurane and fluroxene 
which are not associated with release of catecholamines in normal individuals ${ }^{8}$ and which do not appear to sensitize the myocardium to high levels of circulating catecholamines $^{6-7}$ (although dogs under methoxyflurane anaesthesia have been shown to develop arrhythmias if given large doses of epinephrine intravenously ${ }^{9}$ ) appear to be most advantageous in the management of patients with pheochromocytoma. Review of the published reports of the use of methoxyllurane anaesthesia in these patients ${ }^{3,5,10,11}$ reveals only two instances in which arrhythmias were mentioned. Bain and Spoere ${ }^{10}$ reported that their patient demonstrated occasional premature ventricular contractions, and Crago et al. ${ }^{3}$ reported that a brief episode of slow nodal rhythm occurred during induction in their patient. This latter episode may have been secondary to a fall in arterial pressure to 60 $\mathrm{mm} \mathrm{Hg}$. The use of fluroxene during excision of pheochromocytoma has been reported by two groups. ${ }^{6,12}$ Joas and Craig ${ }^{6}$ noted episodes of nodal rhythm and premature atrial contractions, but no ventricular arrhythmias, in all three of their patients. It appears, therefore, that either methoxyflurane or fluroxene can be used safely in these patients, methoxyflurane having the advantage of providing better abdominal muscle relaxation.

Even when patients with pheochromocytoma have been prepared preoperatively with adrenergic blocking agents, episodes of severe hypertension and/or cardiac arrhythmias may occur during excision of the tumour. This is explained by the fact that preoperative adrenergic block is only partial and merely reduces the responses to high levels of circulating catecholamines which almost uniformly occur during removal of these tumours. ${ }^{5}$ Thus, the anaesthesiologist must be prepared to treat promptly any adrenergic crisis which may ensue. Paroxysmal hypertension may be rapidly controlled with small increments (1-2 mg) of phentolamine intravenously (Fig. 3). Persistent hypertension may be controlled with a continuous infusion of this drug $(10 \mathrm{mg} / 100 \mathrm{ml})$, as suggested by Crout and Brown. ${ }^{5}$ Although many authors feel that sphygmomanometry is adequate for monitoring arterial pressure in these patients, there is little doubt that continuous, direct arterial pressure monitoring simplifies the recognition of sudden changes in arterial pressure and aids in titrating the potent drugs used in managing these episodes.

Serious ventricular arrhythmias (premature ventricular contractions, ventricular tachycardia, or ventricular fibrillation) may occur in these patients even when methoxyflurane or fluroxene is being administered. Most authors have reported little difficulty in controlling such arrhythmias with small doeses of propranolol (2-3 mg) intravenously. ${ }^{1,2}$ Careful monitoring of ventilation, including blood gas determinations, to assure adequate carbon dioxide removal, will help to eliminate hypercarbia as an associated cause of ventricular arrhythmias. ${ }^{11}$

Following the removal of pheochromocytoma, the consequent fall in the levels of circulating catecholamines may result in hypotension. This should be treated initially with rapid infusions of lactated Ringer's solution and/or blood, with careful monitoring of central venous pressure and urinary output. ${ }^{1,2,5}$ If vasopressors become necessary, most authors recommend the continuous infusion of L-norepinephrine $(4 \mathrm{mg} / 500 \mathrm{ml}))^{1,3,5}$ This latter measure is only temporarily necessary in most cases, provided adequate fluid replacement has been achieved. 


\section{SUMMARY}

The anaesthetic management of a patient with pheochromocytoma is discussed. The following points should be considered when treating such patients:

1. Preoperative preparation with adrenergic blocking agents, following the criteria of Harrison et al. ${ }^{4}$

2. Use of an anaesthetic agent (methoxyflurane or fluroxene) which is not associated with release of endogenous catecholamines and does not sensitize the myocardium to high levels of circulating catecholamines.

3. Adequate fluid and blood administration, including preoperative transfusion if necessary.

4. Careful monitoring during surgery, including direct arterial pressure, central venous pressure, electrocardiogram, urinary output, and blood gas determinations.

5. Ready availability of all pharmacological agents appropriate for the control of hypertension, hypotension, and cardiac arrhythmias.

\section{REFERENCES}

1. Ross, E. J.; Puchard, B. N. C.; Kaufman, L.; Ronertson, A. I. G.; \& Harries, B. J. Preoperative and Operative Management of Patients with Phaeochromocytoma. Brit. Med. J. 1: 191 (1967).

2. Cooperman, L. H.; Engelman, K.; \& ManN, P. E. G. Anesthetic Management of Pheochromocytoma Employing Halothane and Beta Adrenergic Blockade: A Report of Fourteen Cases. Anesthesiology. 28: 575 (1967).

3. Crago, R. M.; Eckholdt, J. W.; \& Wiswell, J. G. · Pheochromocytoma: Treatment with Alpha and Beta Adrenergic Blocking Drugs. J.A.M.A. 202: 870 (1967).

4. Harrison, T. S.; Bartiett, J. D., JR.; \& Seaton, J. F. Current Evaluation and Management of Pheochromocytoma. Ann. Surg. 168: 701 (1968).

5. Crout, J. R. \& Brown, B. R., JR. Anesthetic Management of Pheochromocytoma: The Value of Phenoxybenzamine and Methoxyflurane. Anesthesiology. 30; 29 (1969).

6. Joas, T. A. \& Craig, D. Fluroxene Anesthesia for Pheochromocytoma Removal. J.A.M.A. 209: 927 (1969).

7. Pruce, H. L. The Significance of Catecholamine Release during Anaesthesia. Brit. J. Anaesth. 38: 705 (1966).

8. Katz, R. L. \& Epstein, R.A. The Interaction of Anesthetic Agents and Adrenergic Drugs to Produce Cardiac Arrhythmias. Anesthesiology. 29: 763 (1968).

9. Bamfonth, B. J.; SIEbecker, K. L.; Kraemer, R.; \& ORTh, O. S. Effect of Epinephrine on the Dog Heart during Methoxyflurane Anesthesia. Anesthesiology. 22: 169 (1961).

10. Bain, J. A. \& Spoenes, W. E. Methoxyflurane for the Management of Phaeochromocytoma. Canad. Anaesth. Soc. J. 10:481 (1963).

11. Nicholson, M. J.; Watson, R. L.; \& Hansen, H. R. Pheochromocytoma: Cardiac Stability during Methoxyflurane Anesthesia for Surgical Removal. Anesth. \& Analg. 46: 324 (1967).

12. Price, J. H. \& Dornetre, W. H. L. An Assessment of Fluroxene-Epinephrine Compatibility in Man. Anesth. \& Analg. 44: 83 (1965). 